Great caution must be exercised in the acceptance of implements as of glacial age, even if found on the surface of glacial gravels. Men of the later palæolithic age lived only seven miles south of Ware, and there is no reason why they should not have strayed over those high
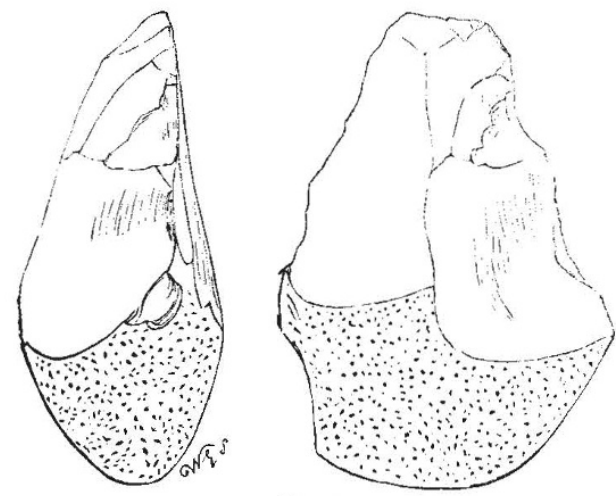

Fig. 7.

positions. Some of the later tools have glacial striæ on the original crust.

There is apparently, but perhaps not really, a gap between each of these three palæolithic periods, as there is apparently a gap between palæolithic (in its vague general sense)

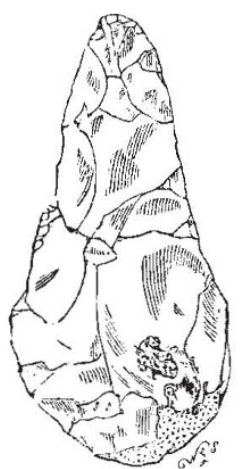

FIG. 8.
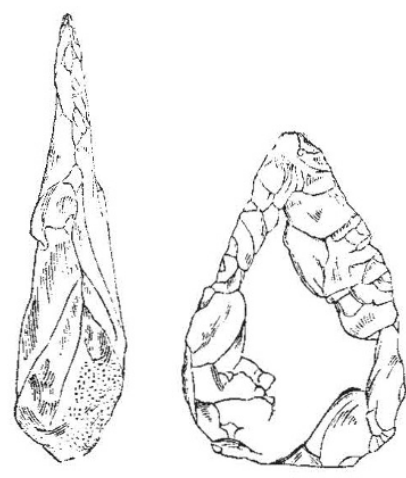

Fig. 9.

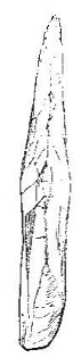

and neolithic times. Each older period however, has forms which foreshadow the forms which follow in succeeding periods even down to neolithic times. No doubt the fossil bones, if a good series could be obtained, would show a succession of, or possibly different groups, of animals

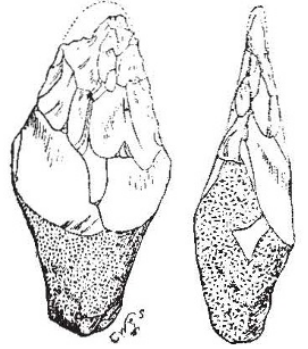

FIG. ro.

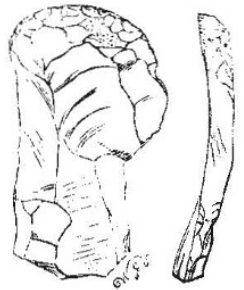

FIG. II. in the different deposits, but the bones, antlers, and teeth met with by me, are at present insufficient to define any such groups with distinctness.

The day will come when we shall know much more of palæolithic men than we know now. At present we only know that such men once existed and made weapons and tools of stone during long periods of time. How or where they first appeared as human creatures we can only guess. When we know more we shall modify our use of such terms as "River Drift Men," "Cave Men," \&c., and we shall probably be able to mark out more or less distinctly a succession of men, a succession of geological events, and a distinct succession of progressive steps in the men from the lowest savage to the barbarian. Some of our ignorance is undoubtedly caused by the undue attention that has been bestowed on the collection of ornate implements and to the employment of gravel-diggers for their collection. No greater mistake can be made than the mere getting together of the more highly-finished and perfect implements. We only learn from them that certain makers, at first few and far between, common at last,- - acquired extraordinary skill in the manufacture of stone tools and weapons. For one perfect example, twenty have their points, butts, or edges injured either by peaceful or warlike work. Collectors
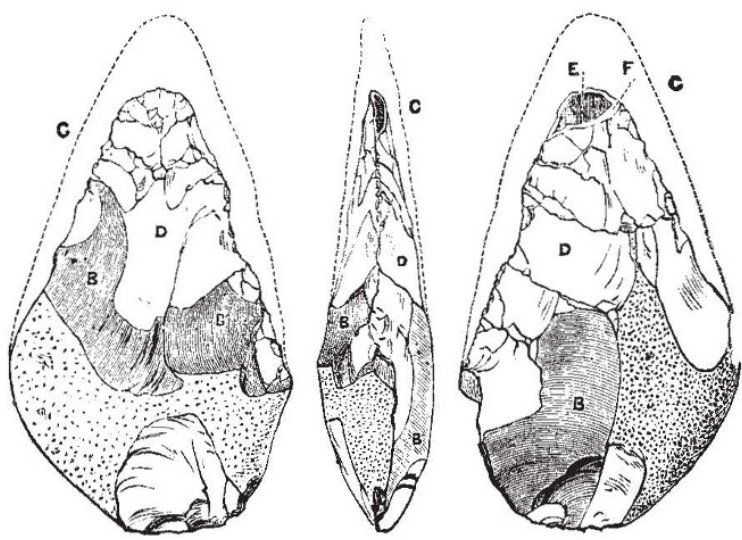

FIG. 12.

will not put the damaged examples and failures in their "cabinets;" but every damage tells some story of the use of the implement, and throws some light on the character of the being who made and used it.

Implements could not have been made without fabricating tools-without punches, hammer-stones, and anvils ; - where the ordinary implements are, these latter things also are. Implements such as are seen in museums are only fit for moderately rough work ; very rough work was sometimes done, but rough and massive stones artificially worked are seldom seen in collections.

Knives, scrapers, wedges, heavy choppers, punches, anvils, cores, abraded hammer-stones, and other things have all been recovered by me from Stoke Newington, London; but as this paper has already exceeded the limits set apart for similar articles, the description and illustration of these less-known objects had better be deferred.

WORTHINGTON G. SMITH

\section{LEVER'S ARC LAMP}

$S^{O}$ many rival forms of lamps have recently been devised for regulating the electric arc light that even specialists in this branch of applied science have some difficulty in keeping up a knowledge of all the various system. Amongst those, however, there is a tolerably well-defined class of lamps in which the movements of the carbon-holder are regulated by a clutch or kindred device, which grips the holder and raises it, lowers it, or releases it when required. Clutch lamps date back, indeed, to the year 1858 , when a lamp of this type invented by Hart, the instrument maker, received a prize from the Royal Scottish Society of Arts. Amongst the more modern forms of clutch lamp those which have bitherto 
found favour with the public are the well-known inventions of Brush and Weston. Though the clutch device is in itself simple and efficient, the difficulty which has beset the action of such lamps has been that of arranging suitable electric mechanism to work the clutch. In Hart's lamp an electro-magnet through the coils of which the main current passed on its way to the lamp, lifted the clutch, and again released it when the increasing resistance of the arc interfered with the strength of the current. In the lamps of Weston and of Brush a much more complicated arrangement was adopted, the magnets which worked the clutch being in both these patterns of lamp wound "differentially," that is to say, with a coil of fine wire connected as a shunt to the lamp, acting in opposition to another coil of thick wire through which the

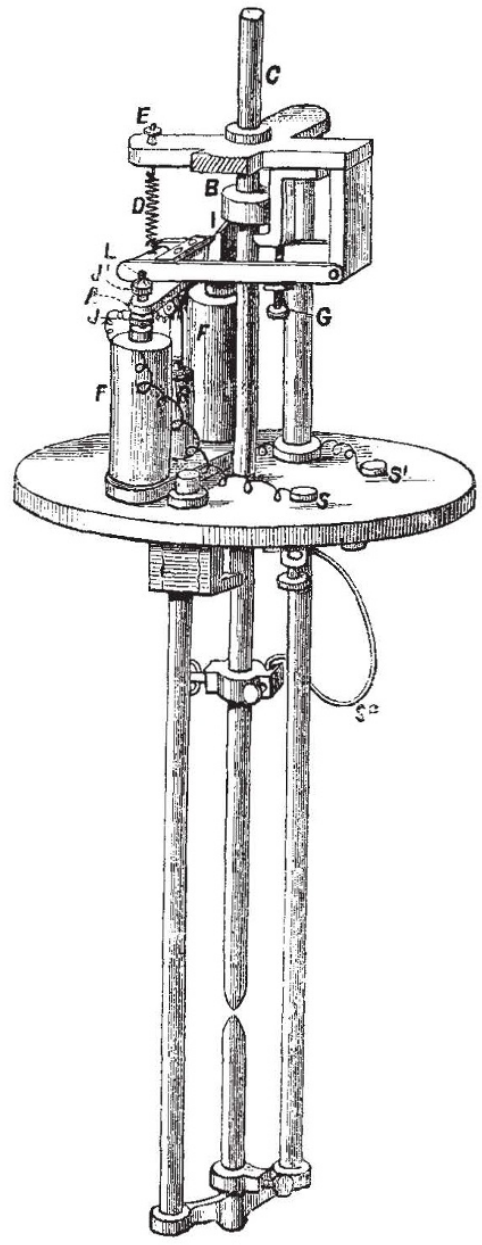

main current flowed. This differential principle was originally applied in the Siemens' lamp, wherein, however, no clutch was used. In the Pilsen lamp, and in many others, combinations of shunt magnets and main. circuit magnets have been similarly applied. The lamp which we illustrate in the figure, the invention of Mr. Charles Lever, of Manchester, is a clutch lamp, but of remarkably simple, yet efficient construction. And as it possesses sundry points worthy of notice from a scientific aspect, we will briefly describe it. The upper carbon is clamped in a holder or carbon rod $\mathrm{c}$, which consists of a tube of brass sliding smoothly through the upper framework of the lamp. Fitting accurately, but not tightly to it, is a brass washer, or collar, $\mathrm{B}$, which is supported from below or on one side by an adjustible screw, $\mathrm{G}$, and on the other by a metal piece, I, projecting from the jointed framework below. This framework is held up by a spiral spring, $\mathrm{D}$, which, when the lamp is not in action, keeps the piece, I, pressed up under the washer, $\mathrm{B}$, and tilts it. When thus tilted it clutches the carbon-holder, $\mathrm{c}$, and raises it. Attached to the under-side of the jointed framework alluded to is an iron bar, A, bearing two broad-ended iron screws, J, below which, again, are seen the two limbs of an electro-magnet, $\mathrm{FF}$, with the poles upward. This electro-magnet is wound with fine wire, and connected as a shunt to the lamp. Now, as described above, when the lamp is not in action, the carbons are held apart by a spring. When the current is turned on it must therefore pass through the shunt magnet, which immediately attracts the bar, A, lowers the piece, I, releases the clutch-washer, B. The upper carbon then falls, and the current is diverted from the shunt-magnet to the lamp itself, passing through the carbons. But when this takes place, the spring, $D$, being no longer opposed, draws up the framework, and picks up the clutch, thus raising the upper carbon through the space requisite for the production of the arc. A more simple or efficient mechanism would be difficult to devise; and its action is extremely regular and steady in practice.

\section{NOTES}

Prof. Huxley has been appointed to deliver the Rede Lecture (Cambridge) this year.

Mr. G. H. DARwin, M.A., F.R.S., has been elected to the Plumian Professorship of Astronomy and Experimental Philosophy at the University of Cambridge, vacant by the death of the Kev. James Challis. This was the first election to a professorship since the approval of the new University Statutes by Her Majesty in Council. By the new statutes the election to certain professorships is vested in a Board nominated by the Special and General Boards of Studies and by the Council of the Senate, the persons so nominated being elected by the Senate. The members of the Board appointed to elect to the Plumian Professorship are the Vice-Chancellor, Prof. H. J. S. Smith, of Oxford, Mr. W. H. M. Christie, the AstronomerRnyal, Mr. W. Spottiswoode, President of the Royal Society ; Professors Adams, Stokes, Cayley ; Dr. Ferrers, Master of Gonville and Caius; and Mr. Isaac Todhunter, of St. John's.

ThE subscription for the Darwin Memorial has awakened so much enthusia:m in Sweden that the local committee there formed has received subscriptions from no less than 1400 persons, including " all sorts of people," writes Prof. Loven in a letter to the English Committee, "from the bishop to the seamstress," the sums varying from five pounds to twopence. The English Committee, which has its head-quarters at the Royal Society, London, has now recsived (inclusive of subscriptions from abroad), 4000l., but the number of subscribers in the United Kingdom is only about 600. From this it would seem that an interest in science is not nearly so widely spread in Britain as it is in the more thinly peopled land of Sweden.

IN announcing the death of $\mathrm{Mr}$. Darwin to the American Philosophical Society at its meeting on April 21, 1882, Dr. Le Conte stated the general bearing of Darwinism in a striking and unusual way:- "To no man more than to Darwin does the present age owe as much, for the gradual reception of the modern method of close observation over the scholastic or a priori formulæ, which, up to a brief period, affected all biological investigations. To him, above all men, we owe the recurrence to the old Aryan doctrine of evolution (though in those ancient times promulgated under the guise of inspiration) as preferable, by reasonable demonstration, to the Semitic views, which have prevailed to within a few years, and are still acceptable to a large number of well-minded but unthinking men. The doctrine 